\title{
Variatio delectat
}

\author{
Vom 10. April bis 2. Mai 2010 zeigten malende Ärzte des Vereins «Kunstausstel- \\ lung der Schweizer Ärzte» / «Salon des Médecins Suisses»* ihre Bilder in der Stiftung \\ Rüttihubel-Bad bei Worb.
}

\section{David Künzler}

Präsident Kunstausstellung der Schweizer Ärzte

\footnotetext{
* www.aerzte-kunst.ch

** www.jerryrojas.ch

*** www.unicef.ch
}

Korrespondenz: Dr. med. David Künzler Jakob Zürrerstr. 35 CH-8915 Hausen am Albis Tel. 0447640472 dkkuenzler@bluewin.ch info@aerzte-kunst.ch
«Die Medizin ist eine Kunst», ist auf der Homepage der Vereinigung «Kunstausstellung der Schweizer Ärzte» zu lesen, die vor mehr als 50 Jahre gegründet wurde. Als Kunst hat die Medizin viele Verbindungen zu den andern Künsten wie dem Schreiben, Musizieren, Komponieren usw. - und eben auch zur Malerei. Obwohl die Werke, die wir schaffen, nicht unserer hauptberuflichen Tätigkeit entspringen, entstehen doch bemerkenswerte Bilder.

Die Vereinigung wurde gegründet, um unkompliziert, auch ohne Verkauf, ausstellen zu können. Diesem Zweck wurde in der bisherigen Vereinsgeschichte denn auch jedes Jahr entsprochen. Da die Qualität der Bilder dies nahelegt, werden gelegentlich aber auch Verkaufsausstellungen wie die in diesem Beitrag vorgestellte organisiert. Dabei ist es uns ein Anliegen, einen Teil des Profits einer im weitesten Sinn humanitären oder sozialen Institution zukommen zu lassen (siehe Kasten).

\section{Unterstützung der Unicef-Aktion gegen Mädchenbeschneidung}

Ein Teil des Verkaufserlöses aus der hier vorgestellten Ausstellung kam der Aktion der Unicef im Kampf gegen die Mädchenbeschneidung ${ }^{* * *}$ zugute. Als Ärzte sollten wir das Unmenschliche solcher Praktiken und die Brutalität ihrer Konsequenzen sehr gut verstehen. Leider ist dieser grausame Ritus an gewissen Orten immer noch tief verwurzelt.

Vor 40 Jahren hat der Autor einige Jahre in einem Spital in Nord-Ost-Ghana gearbeitet und traf dort in der Geburtshilfe oft auf die Situation, dass eine Frau eine Beschneidung in der Jugend hinter sich hatte. Eine vaginale Geburt war dann oft sehr schwer oder unmöglich. Leider kamen die Frauen aus den Dörfern der Region meist erst ins Spital, wenn es nicht mehr anders ging. Für effiziente Hilfe war es unter diesen Umständen meist zu spät, und das Kind starb oder dieses Schicksal ereilte gar Mutter und Kind. Genaue Zahlen zu solchen Ereignissen gibt es nicht. Veränderungen sind sehr schwierig zu erreichen, und da solche Praktiken kulturell tief verwurzelt sind, muss sehr behutsam vorgegangen werden.

$(d k)$

\section{Vielfalt an Sujets und Techniken}

In der Sammelausstellung kommt eine enorme Vielfalt an Techniken, Sujets, Formaten und Grössen zusammen. Variatio delectat, sagten die Römer, «Abwechslung macht Freude». Für Abwechslung sorgte auch Jerry Rojas, Kardiologe und Gitarrist**, der den Auftakt zur Ausstellung mit sensibler, zum Teil meditativer Musik bereicherte.

Manche Besucher empfinden ein derart breites Spektrum von Stilen und Bildern verschiedener Künstlern als verwirrlich. Meinerseits habe ich Freude daran, einerseits weil ich die Abwechslung, die Variation liebe, anderseits, weil die Verschiedenheiten in gewisser Weise ein Abbild der Menschheit sind.

Ärzte sind mit dieser Vielfalt täglich konfrontiert: Je nach Frequenz haben wir alle Viertel- bis Halbstunde einen andern Menschen vor uns, mit immer wieder andern Beschwerden. Manches ist offensichtlich, manches eher versteckt. Für Transparenz (im wahrsten Sinn) kann eine Röntgenaufnahme sorgen - oder heute eher ein Computertomogramm, Ultraschall und andere bildgebende Verfahren. Mehr Schwierigkeiten bereitet oft die Transparenz bei der Psyche: Diese ist letztlich nicht durchsichtig, obwohl gerade sie ja eigentlich immateriell ist.

\section{Sich in die Bilder einfühlen}

Dies aber kann auch bei Bildern der Fall sein: «Was hätt' er / hätt si wele säge mit dem - komische - Bild? Ich gseen do nüüt, won ich verstoo!» Möge es der Betrachter den Künstlern nicht übelnehmen, wenn dem so ist. Man muss sich oft in den Patienten oder eben in das Bild einsehen, einfühlen - und plötzlich dämmert es, kommt das sogenannte Aha-Erlebnis. Verzweifle man also nicht an scheinbar Unverständlichem.

Man kann aber auch einmal weitergehen und das Gesehene ohne Erklärung lassen. Auch in diesem Punkt gibt es Parallelen zu unserem Beruf: Manchmal muss man eine erste Diagnose unfertig stehenlassen und die weitere Entwicklung verfolgen. Man kann es machen wie wir Ärzte: einen Patienten nach dem andern anschauen, ihn so nehmen, wie er ist, und nicht den einen mit dem andern vergleichen wollen. So soll man es auch mit den einzelnen Künstlern und ihren Bildern machen. 


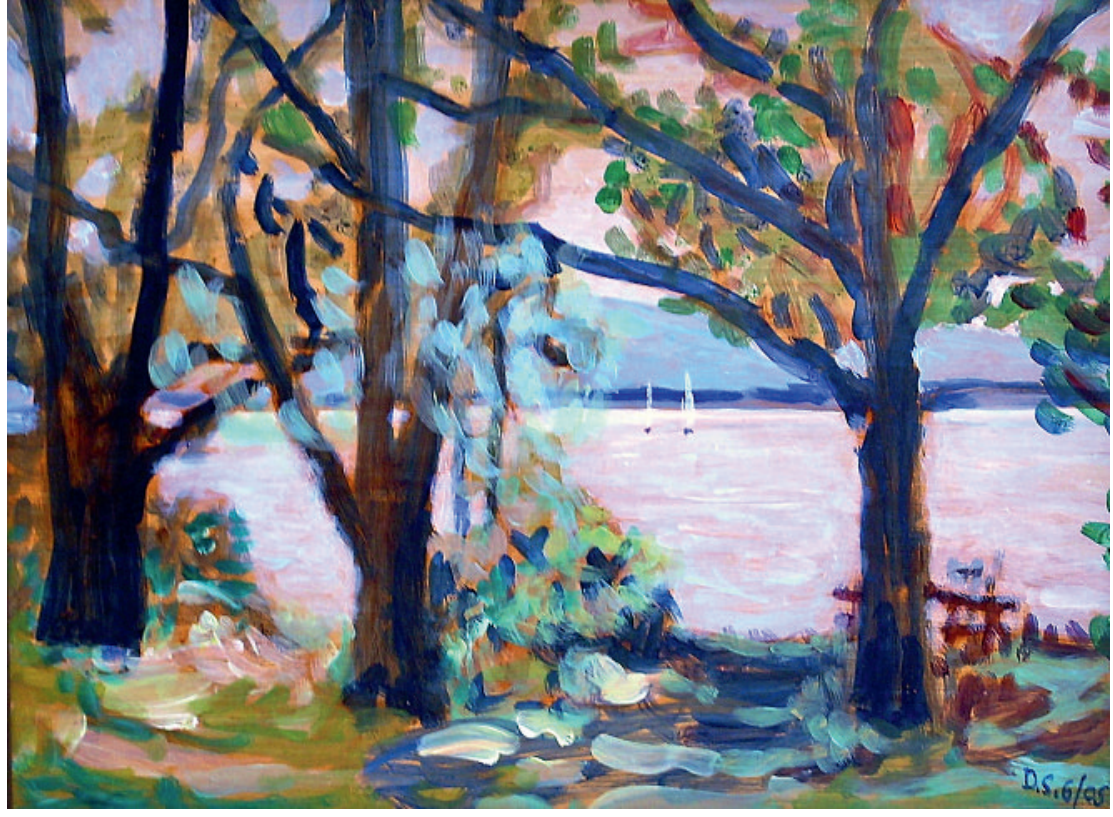

Dieter Schwenk, Blumberg (D): Herbst am Bodensee (Acryl).

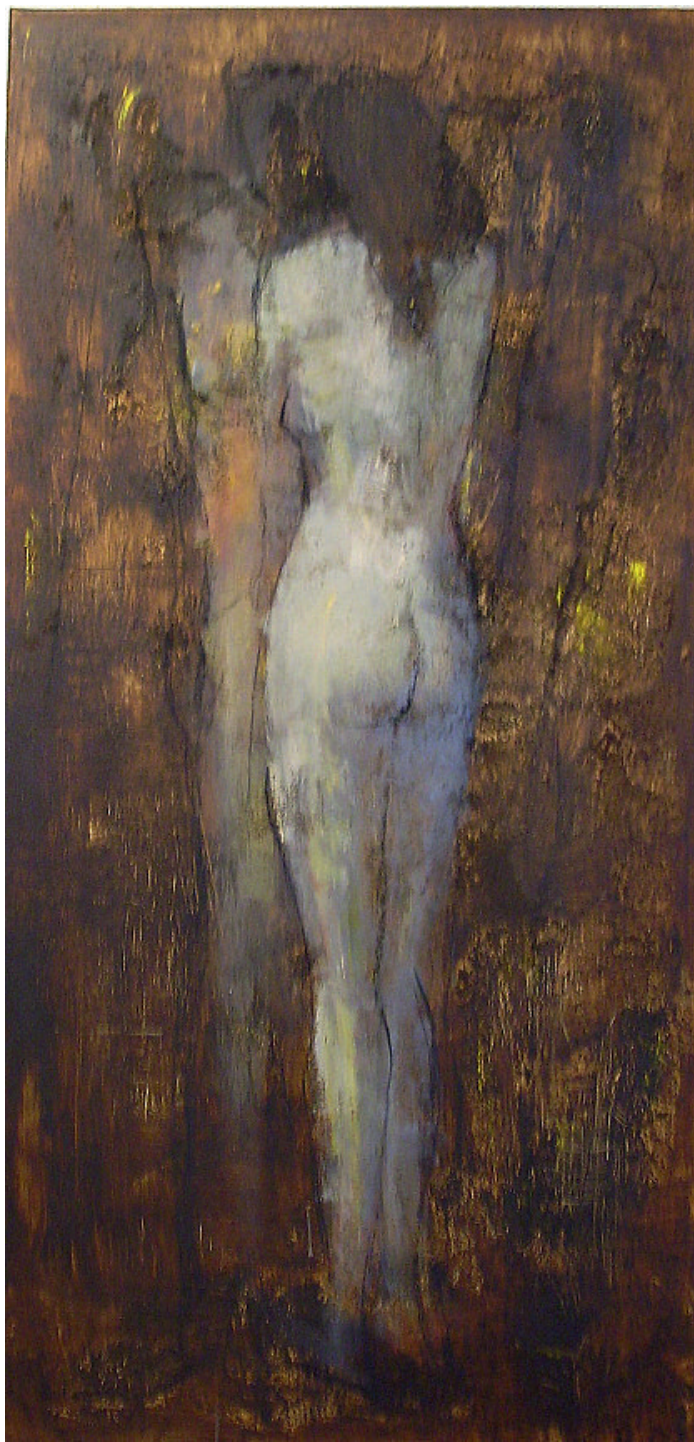

Christa Ritter, Basel: Symbiose (Mischtechnik).

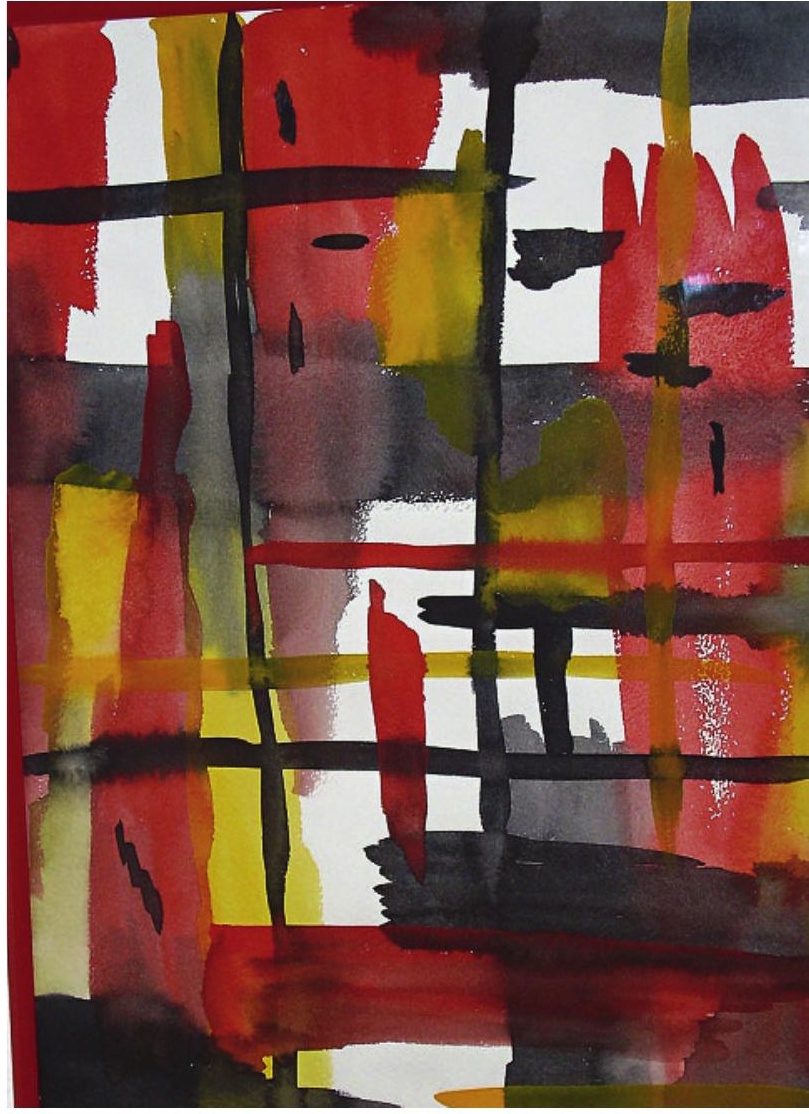

David Künzler, Hausen am Albis: Kreuzungen (Acryl).

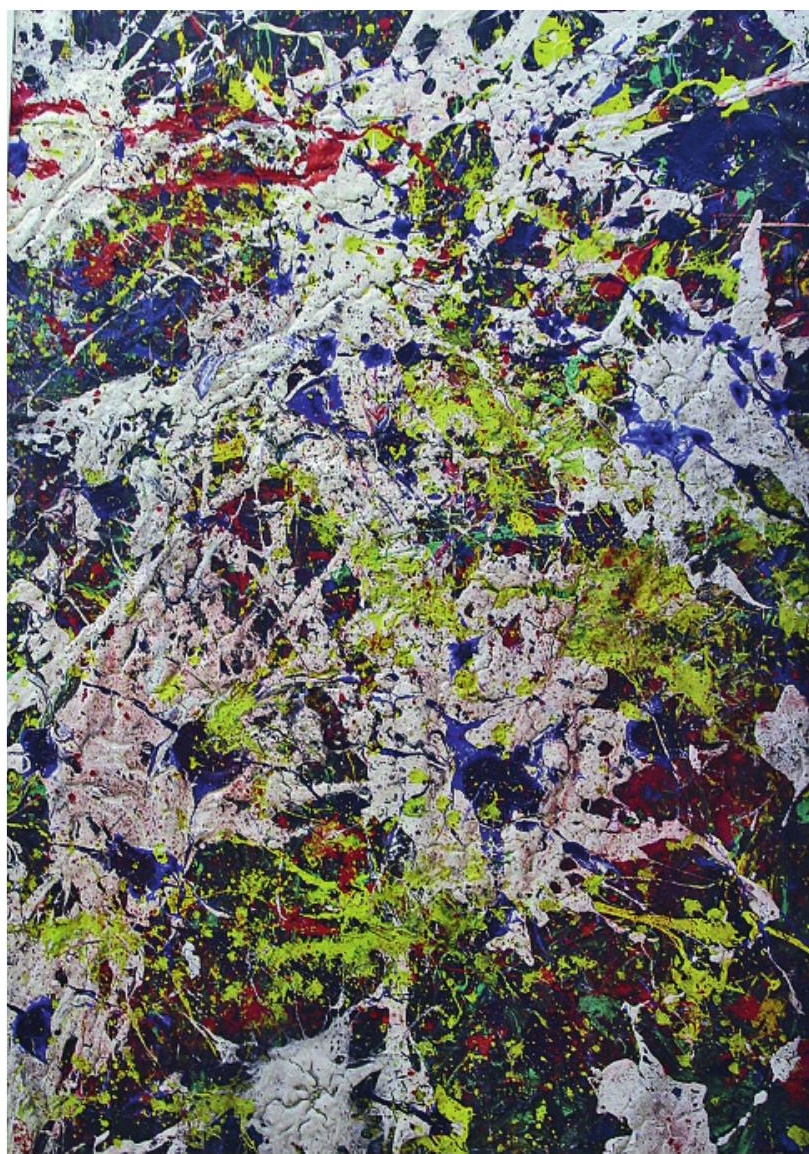

Roland Hofer, Basel: Le commencement (Mischtechnik). 